\title{
Influence of Connecting Two Standalone Mobile Three- Dimensional Scanners on Accuracy Comparing with a Standard Device in Facial Scanning
}

\author{
Ali Modabber ${ }^{1, a}$, Florian Peters ${ }^{1, a}$, Anna Brokmeier ${ }^{1}$, Evgeny Goloborodko ${ }^{1}$, Alireza Ghassemi ${ }^{1}$, \\ Bernd Lethaus $^{1}$, Frank Hölzle ${ }^{1}$, Stephan Christian Möhlhenrich ${ }^{1}$ \\ ${ }^{1}$ Department of Oral, Maxillofacial and Plastic Facial Surgery, School of Medicine, University Hospital RWTH Aachen, \\ Aachen, Germany. \\ ${ }^{\mathrm{a} B o t h}$ first authors contributed equally.
}

\author{
Corresponding Author: \\ Ali Modabber \\ Department of Oral, Maxillofacial and Plastic Facial Surgery, School of Medicine \\ University Hospital RWTH Aachen \\ Pauwelsstr. 30, 52074 Aachen \\ Germany \\ Phone: $+49241 / 80-88231$ \\ Fax: $+49241 / 80-82430$ \\ E-mail: amodabber@ukaachen.de
}

\begin{abstract}
Objectives: In this study is investigated if bundling of two scanners leads to better accuracy in recording faces than a standard face-scanning device.

Material and Methods: In a group of 28 volunteers, two test specimens were attached to their faces: one on their forehead and one turned $90^{\circ}$ on their cheek. Each volunteer was scanned by FaceScan $3 \mathrm{D}^{\circledR}$ and two bundled Artec EVA ${ }^{\circledR}$ Scanners. The $^{\circ}$ scans were aligned to a three-dimensional model of the test specimen, and the mean error was recorded. Length, width and angles between the test specimen's planes were compared.

Results: The mean deviation is significantly lower for the cheek test specimen in alignment $(\mathrm{P}<0.001)$, length and width $(\mathrm{P}<0.001)$ but not for the forehead test specimen in alignment and length and width $(\mathrm{P}>0.05)$ using FaceScan3D ${ }^{\circledR}$. The aberration from the original angle between two sides of the test specimen is significantly lower measured with Artec EVA ${ }^{\circledR}$ for the angle between the front and the bottom plane of both test specimens $(\mathrm{P}<0.01)$. Besides the angle between the right plane and the bottom plane as well as the top plane of the test specimen mounted to the cheek, the deviation of the angle between the other side planes to each other is significantly lower $(\mathrm{P}>0.05)$ scanned with Artec $\mathrm{EVA}^{\circledR}$.

Conclusions: Compared to FaceScan $3 \mathrm{D}^{\circledR}$, two bundled Artec EVA ${ }^{\circledR}$ scanners provide different accuracies depending on the location of the measured parameters. The accuracy measured for both scanners is inside the range found in the literature.
\end{abstract}

Keywords: dimensional measurement accuracy; three-dimensional imaging; optical devices.

Accepted for publication: 28 October 2016

To cite this article:

Modabber A, Peters F, Brokmeier A, Goloborodko E, Ghassemi A, Lethaus B, Hölzle F, Möhlhenrich SC.

Influence of Connecting Two Standalone Mobile Three-Dimensional Scanners on Accuracy Comparing with a Standard

Device in Facial Scanning

J Oral Maxillofac Res 2016;7(4):e4

URL: http://www.ejomr.org/JOMR/archives/2016/4/e4/v7n4e4.pdf

doi: 10.5037/jomr.2016.7404 


\section{INTRODUCTION}

Today, numerous new technological methods are used in medicine $[\underline{1}, \underline{2}]$. A common one is capturing threedimensional surface data of patients. These data can be used for different purposes such as planning for surgical treatment, visualizing complex procedures for the patient or comparing the patient's outcome after treatment [3-7]. At present there are different techniques for acquiring the three-dimensional data available in the market [8]. Using a computed tomography (CT) or magnetic resonance imaging scanner results in detailed three-dimensional data from the inside and the outside of the patient [9]. Major disadvantages are the limited availability, high costs, and in the case of CT, a lot of ionizing radiation. For receiving three-dimensional data from the outer surface of the patients, coordinate measuring machines have been used. Even this technique comes with the disadvantage of touching the patient. Another alternative is using a laser scanner or a scanner that uses structured light for capturing its data. Currently, numerous devices are available in the market and are used in medicine. To increase their share of the market, manufacturers develop new features that should make their devices more attractive. All of them say that their product leads to the best result.

Recently, three-dimensional data of the human face have been increasingly used. Receiving exact threedimensional surface data of the human face is not trivial. The face consists of different complicated and fine geometric structures. Even if it is possible to capture the face with some devices, there are few literature reviews to evaluate their accuracy $[\underline{4}, \underline{8-}$ 14]. For this study, we have chosen two optical three-dimensional scanners using structured light. FaceScan3D ${ }^{\circledR}$ (3D-Shape GmbH, Erlangen, Germany) is already commonly used in literature [ㄱ, 15-18]. The other device, Artec EVA ${ }^{\circledR}$ (Artec Group, Luxembourg, Luxembourg), has not been used for medical purposes that often. Until now, it has been used in the technical environment [19-22].

In this study, the accuracy achieved by two coupled Artec $\mathrm{EVA}^{\circledR}$ scanners against the accuracy achieved by a FaceScan $3 \mathrm{D}^{\circledR}$ is compared. The aim is to evaluate if investing in two scanners and setting up a bundle for scanning results in significantly more precise scans.

\section{MATERIAL AND METHODS}

The study was conducted according to the declaration of Helsinki. After institutional approval of the ethics committee of University Hospital RWTH Aachen, Aachen, Germany (EK 168/16), written informed consent was obtained from a group of 28 volunteers consisting of 16 females and 12 males. None of them underwent facial surgery, were suffering severe facial malformation or were afflicted with a seizure disorder triggered by flashing lights.

\section{Artec EVA ${ }^{\circledR}$}

Artec EVA ${ }^{\circledR}$ is a mobile three-dimensional scanning device. According to the technical data provided by the Artec Group the scanner is small $(261.5 \mathrm{~mm}$ $\times 158.2 \mathrm{~mm} \times 63.7 \mathrm{~mm})$ and lightweight $(800 \mathrm{~g})$. It was designed for creating three-dimensional models of huge objects that do not fit into common threedimensional scanners. Another feature of this device is that it can create a bundle with up to four scanners of the same type or even third party scanners. The number of scanners that can be bundled is limited to the amount of processors mounted inside the scanning PC. Every scanner uses its own thread. Pursuant to the manual, scanners used in bundles have to be set up in defined positions to each other. The field of view must overlap each other. For acquiring surface information, structured light is used. On account of this, the scanner consists of a projector, a colour camera and two black and white $(\mathrm{b} / \mathrm{w})$ cameras. A striped pattern is projected on the surface of the scanned object and is recorded by the b/w cameras mounted in different but known positions. The texture is recorded by the colour camera in the middle of the scanner. Using this technique, Artec $\mathrm{EVA}^{\circledR}$ records up to 16 frames per second. The data is sent to every personal computer (PC) connected to the scanner. The software Artec Studio 9.2 (Artec Group, Luxembourg, Luxembourg) aligns all frames captured to each other regarding three-dimensional surface data and texture information. Next, the frames can be fused to a three-dimensional model and can be provided with a coloured texture. Finally, a three-dimensional model consisting of triangles can be exported as Stereolithography (.stl) or Wavefront Object (.obj). For mapping the texture to the object, a Material Template file (.mtl) is created. Texture data is stored in a Joint Photographic Experts Group Interchange Format (.jpg).

\section{FaceScan3D $^{\circledR}$}

FaceScan3D ${ }^{\circledR}$ is a stationary three-dimensional scanner. It consists of a mirror construction around the patient, and on the opposite side is a case with two $\mathrm{b} / \mathrm{w}$ cameras, a projector, a standard digital 
photo camera and two professional flashes. For controlling and post-processing, a standard PC is used, which is a part of this scanner. The scanner case and the mirror construction are fixed to the bottom so it is not possible to move them around. For acquiring the three-dimensional surface data, the scanner also uses the structured light technique. The projector displays different striped patterns on the volunteer's face. These patterns are recorded by the two b/w cameras mounted in different known positions. Next, a photograph is taken by the photo camera for creating a texture. While taking the photograph, the volunteer is illuminated by the flashes. Because of the mirror construction around the volunteers head, it is possible to get a $180^{\circ}$ three-dimensional picture of the volunteer with only capturing the volunteer once. Recording this image takes $800 \mathrm{~ms}$ according to the technical data provided by 3D-Shape. After taking the image, the data is postprocessed on a common PC. Finally, a Wavefront Object (.obj) together with a coloured texture in a Joint Photographic Experts Group Interchange Format (.jpg) and a Material Template file (.mtl) is exported.

\section{Test specimen}

During the scans, two test specimens were mounted to the volunteers' faces. As a specimen, ordinary $4 \times 2$ Lego (LEGO A/S, Billund, Denmark) bricks were chosen. Every brick has a length of $30.8 \mathrm{~mm}$ and a width of $15.8 \mathrm{~mm}$. Every plane is angled $90^{\circ}$ to another plane. Before using the brick as a test specimen, they were dulled using Perlablast $50 \mu \mathrm{m}$ (BEGO, Bremen, Germany) blast-cleaning abrasive.
A pressure of 0.5 bar was used for dulling them. After this, every brick was measured with a digital caliper (Mitutoyo Deutschland GmbH, Neuss, Germany). No differences in its original length and width could be measured. The uncertainty of measuring, according to the technical data provided by Mitutoyo, was $\pm 0.02 \mathrm{~mm}$.

\section{Study protocol}

Two test specimens were attached to every volunteer's face. One of the test specimens was mounted to the middle of the volunteers' forehead, and the other one was turned $90^{\circ}$ to the right prominence of the cheekbone (Figure 1). All further scanning took place in the same room. The volunteers were asked to sit down inside the mirror construction of FaceScan3 ${ }^{\circledR}$. Volunteers were aligned to the cross displayed by FaceScan $3 \mathrm{D}^{\circledR}$. Before taking the three-dimensional picture, volunteers were asked to relax their mimics and look towards the scanning device responsible for recording the texture of the later three-dimensional model. Adjacent to that, the volunteers sat down on a chair to be scanned by two Artec EVA ${ }^{\circledR}$ scanners. Both Artec EVA ${ }^{\circledR}$ scanners were mounted on a tripod $1.3 \mathrm{~m}$ in height and were calibrated using a test volunteer. Before scanning, the volunteer on the chair was aligned at $1.3 \mathrm{~m}$ with its nose tip. According to the technical data of Artec EVA $^{\circledR}$, the distance between the volunteer and both of the scanners was set to 70 $\mathrm{cm}$, which is the middle of the working distance. The volunteers were asked to relax their mimics again, and the scan was started.

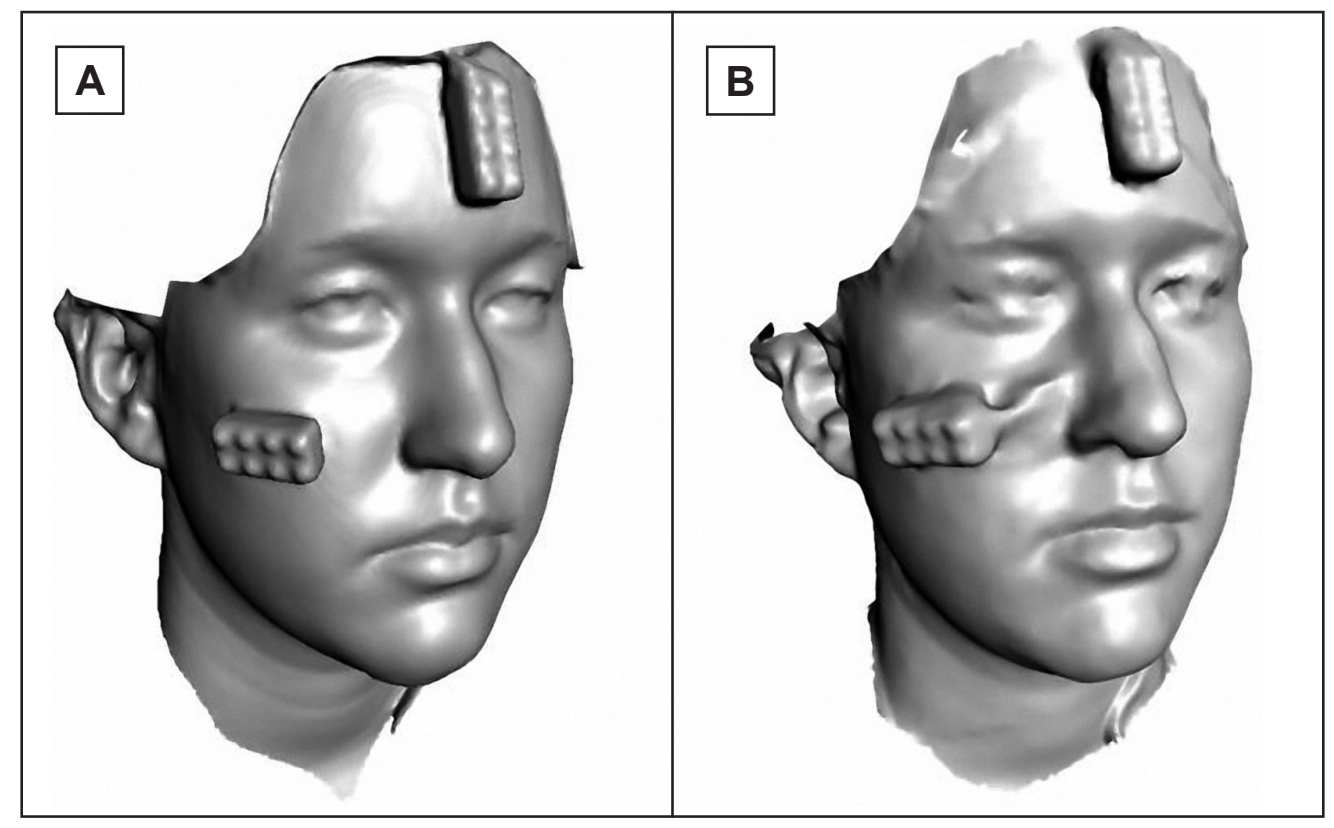

Figure 1. Example of volunteer with test specimen mounted to the volunteer's face. $\mathrm{A}=$ scanned with FaceScan $3 \mathrm{D}^{\circledR} ; \mathrm{B}=$ scanned with Artec $\mathrm{EVA}^{\circledR}$ bundle. 


\section{Three-dimensional analysis}

For analysing the three-dimensional models taken from the volunteers, the obj data was imported into Geomagic Control 2014 Software (3D Systems Corporation, Rock Hill, USA) running on a Fujitsu Siemens PC (Fujitsu Siemens Computers, Munich, Germany). For measuring the overall accuracy achieved, a three-dimensional model of a $4 \times 2$ Lego brick with its original dimensions was imported. Subsequently, the three-dimensional model of the Lego brick automatically was fitted to the recorded data by the best fit function. The average error is reported (Figure 2). Afterwards, the planes of the scanned test specimen were marked by the same experienced user (FP), and an equalisation plane was created by Geomagic Studio. The dimensions in length and width, angles of the side planes to the neighbouring ones and angles between the top plane and the side planes were measured.

\section{Statistical analysis}

Three-dimensional model results were reported by an experienced rater (FP), repeating his assessment 4 weeks later to determine the intrarater reliability. GraphPad Software Quick Calcs (GraphPad Software, Inc. La Jolla, USA) was used to estimate Fleiss Kappa statistics for the intrarater reliability calculations.

Statistical analyses of the measured values were performed using the Statistical Package for Social Sciences SPSS v23 (IBM, Chicago, IL, USA) running on a Fujitsu Siemens PC (Fujitsu Siemens Computers, Munich, Germany). The Shapiro-Wilks normality test and the Levene variance homogeneity test were applied to the data. The data was normally distributed, and there was homogeneity of variance among the groups. For statistical analysis, the Student t-test was used. The level of significance was set at $\mathrm{P} \leq 0.05$. All data are expressed as mean and standard deviation (M [SD]).

\section{RESULTS \\ Intra-observer reliability}

Intra-observer reliability was substantial $(\kappa=0.61$ $-0.8)$.

\section{Alignment}

Automatic alignments of the scanned test specimen and the model of the Lego brick resulted in errors of

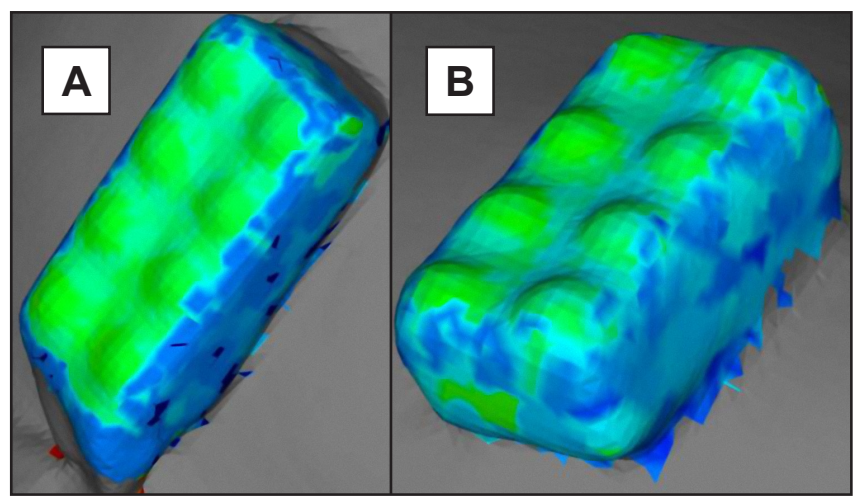

Figure 2. Sample of automatic alignment of the reference Lego brick scanned with FaceScan $3 \mathrm{D}^{\circledR}$.

$\mathrm{A}=$ forehead; $\mathrm{B}=$ check.

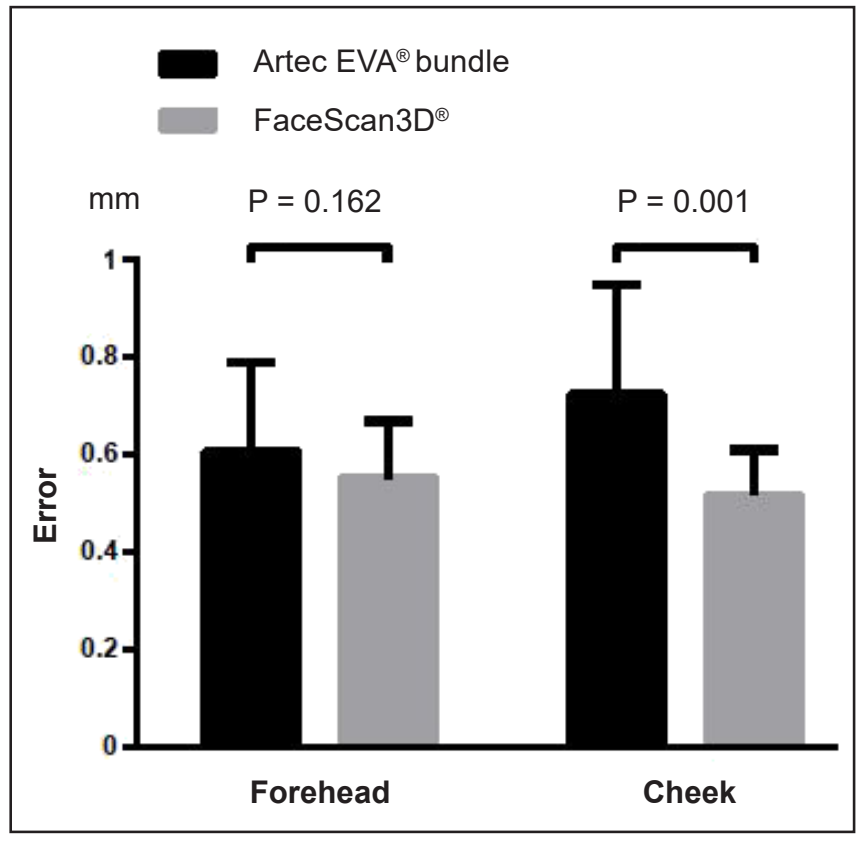

Figure 3. Boxplot showing mean error in best fit alignment of the test specimen (mm) in scans using Artec EVA ${ }^{\circledR}$ and FaceScan $3 \mathrm{D}^{\circledR}$, as well as corresponding P-values.

$0.605(0.183) \mathrm{mm}$ for the forehead test specimen and $0.722(0.225) \mathrm{mm}$ for the cheek test specimen scanned with a bundle of two Artec EVA ${ }^{\circledR}$ scanners. Scanning with FaceScan $3 \mathrm{D}^{\circledR}$ resulted in mean errors of $0.551(0.118) \mathrm{mm}$ for the forehead test specimen and $0.517(0.092) \mathrm{mm}$ for the test specimen mounted to the cheek of the volunteer. The difference between the two scanners for the alignment error is not significant for the test specimen mounted to the forehead $(\mathrm{P}=0.162)$. The error for the test specimen mounted to the cheek differs significantly $(P=0.001)$ between the two scanner systems (Figure 3).

\section{Length and width}

The mean deviations from the original length and 
Table 1. Mean deviation (M [SD]) of length and width according to original in $\mathrm{mm}$

\begin{tabular}{c|c|c|c|c|c|c}
\hline \multirow{2}{*}{} & \multicolumn{2}{|c|}{ Artec EVA $^{\circledR}$ bundle } & \multicolumn{2}{c|}{ FaceScan3D $^{\circledR}$} & \multicolumn{2}{c}{ P-values } \\
\cline { 2 - 7 } & Forehead & Cheek & Forehead & Cheek & Forehead & Cheek \\
\hline Length & $2.48(1.619)$ & $5.968(4.965)$ & $2.066(2.537)$ & $0.543(0.528)$ & $0.462^{\mathrm{b}}$ & $<0.001^{\mathrm{a}}$ \\
\hline Width & $1.228(1.276)$ & $2.311(2.151)$ & $0.839(0.672)$ & $0.414(0.288)$ & $0.23^{\mathrm{b}}$ & $<0.001^{\mathrm{a}}$ \\
\hline Total & \multicolumn{2}{|c|}{2.997} & \multicolumn{2}{c}{0.966} & & \\
\hline
\end{tabular}

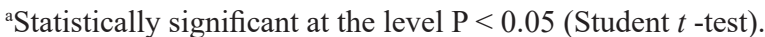

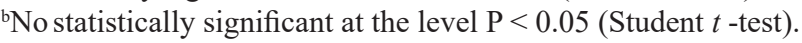

$\mathrm{SD}=$ standard deviation.

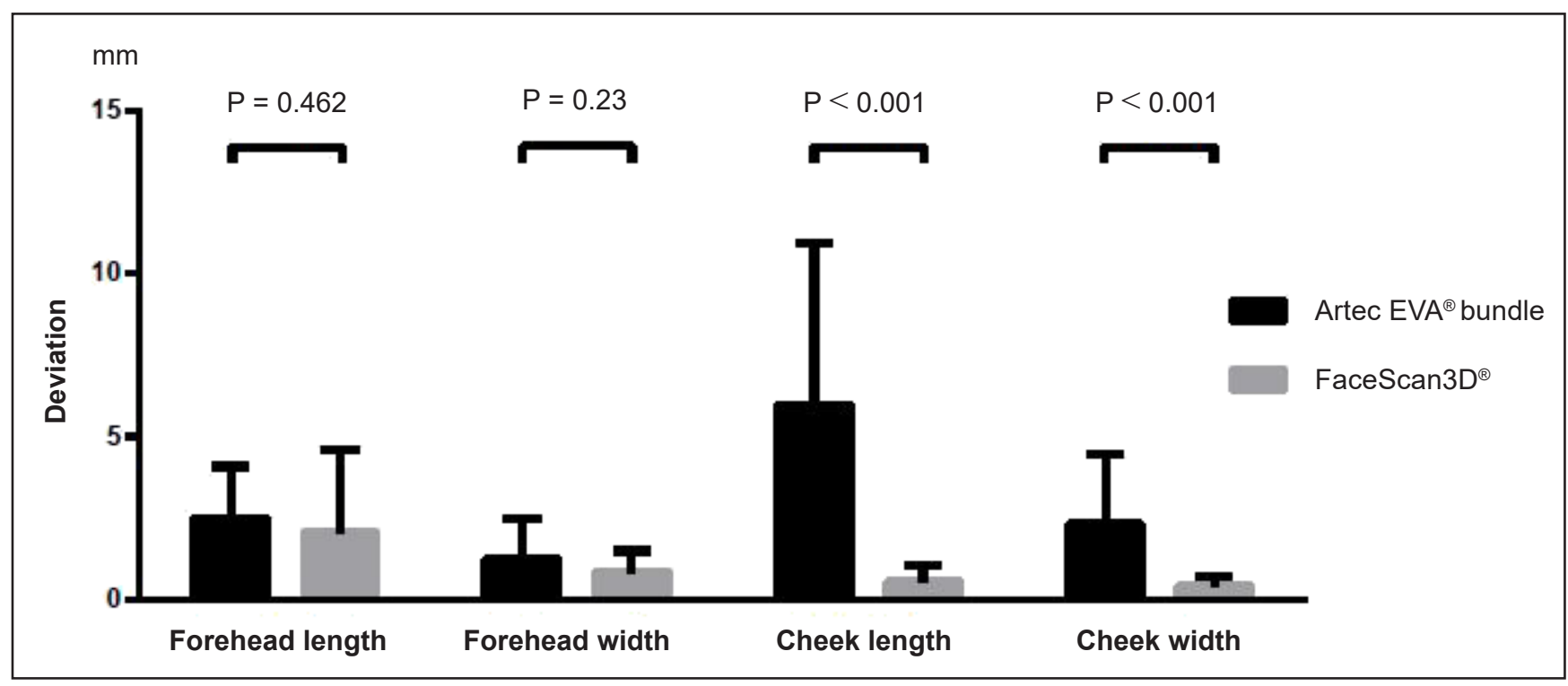

Figure 4. Boxplot showing mean deviation in length and width of test specimen (mm) in scans using Artec $\mathrm{EVA}^{\circledR}$ and FaceScan $3 \mathrm{D}^{\circledR}$, as well as corresponding P-values.

Table 2. Mean deviation (M [SD]) of angles from sides to front plane according to original in degree

\begin{tabular}{l|c|c|c|c|c|c}
\hline & \multicolumn{2}{|c|}{ Artec EVA ${ }^{\circledR}$ bundle } & \multicolumn{2}{c|}{ FaceScan3D $^{\circledast}$} & \multicolumn{2}{c}{ P-values $^{\text {Cheek }}$} \\
\hline Angle front to & Forehead & Cheek & Forehead & Cheek & Forehead & Cheek \\
\hline Top plane & $24.461(10.583)$ & $14.025(8.326)$ & $19.878(11.484)$ & $13.488(10.598)$ & $0.108^{\mathrm{b}}$ & $0.417^{\mathrm{b}}$ \\
\hline Bottom plane & $7.745(5.055)$ & $16.443(7.63)$ & $13.053(9.223)$ & $27.372(14.104)$ & $0.006^{\mathrm{a}}$ & $<0.001^{\mathrm{a}}$ \\
\hline Left plane & $5.041(7.11)$ & $5.111(4.717)$ & $3.642(3.012)$ & $14.726(10.865)$ & $0.27^{\mathrm{b}}$ & $<0.001^{\mathrm{a}}$ \\
\hline Right plane & $4.086(2.653)$ & $17.784(12.296)$ & $3.93(4.179)$ & $7.029(7.17)$ & $0.871^{\mathrm{b}}$ & $<0.001^{\mathrm{a}}$ \\
\hline
\end{tabular}

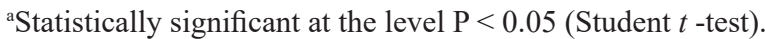

${ }^{\mathrm{b}}$ No statistically significant at the level $\mathrm{P}<0.05$ (Student $t$-test).

$\mathrm{SD}=$ standard deviation .

width for the test specimen mounted to the volunteers' foreheads and the volunteers' cheeks are shown in Table 1. The difference in length and width do not differ significantly (length: $\mathrm{P}=0.462$; width: $\mathrm{P}=0.23$ ) between the two scanning systems used for the test specimens stuck to the volunteers' foreheads. For the length and width of the test specimens attached to the volunteers' cheeks, FaceScan3 $\mathrm{D}^{\circledR}$ shows a significantly lower $(\mathrm{P}<0.001)$ error than Artec $\mathrm{EVA}^{\circledR}$ (Figure 4).

\section{Angles between front plane and side planes}

The deviations from the original angle of $90^{\circ}$ between the front plane and the side planes for both test specimens measured with Artec $\mathrm{EVA}^{\circledR}$ and FaceScan $3 \mathrm{D}^{\circledR}$ are shown in Table 2. The angle between the front plane and the bottom plane of the Lego brick on the volunteers' foreheads is measured significantly more accurately $(\mathrm{P}=$ $0.006)$ by Artec EVA $^{\circledR}$ than by FaceScan $3 D^{\circledR}$. 
The deviation between the other planes and the front plane of the test specimen at the volunteers' foreheads do not differ significantly $(\mathrm{P}=0.108$, $\mathrm{P}=0.27, \mathrm{P}=0.871$ ) between both scanning systems used. The deviations from the original angle measured between the front planes and the bottom planes as well as between the front planes and the left planes for the test specimen at the volunteers' cheeks are significantly lower $(\mathrm{P}<0.001)$ when measured with Artec $\mathrm{EVA}^{\circledR}$. The aberration metered between the original angle of $90^{\circ}$ and the one measured on the scan for the angle between the front plane and the right plane is significantly lower $(\mathrm{P}<0.001)$ when measured with FaceScan $3 \mathrm{D}^{\circledR}$. The discrepancy between the original angle and the measured one between the front plane and the top plane for the test specimen mounted to the cheek is not significantly different $(\mathrm{P}=0.417)$ between scanning with Artec $\mathrm{EVA}^{\circledR}$ or FaceScan3D ${ }^{\circledR}$ (Figure 5).

\section{Angles between side neighbouring side planes}

The aberrations between the original angle of $90^{\circ}$ between neighbouring side planes and the angles measured at the scans taken with Artec EVA ${ }^{\circledR}$ and FaceScan3D ${ }^{\circledR}$ are shown in Table 3. All angles between the neighbouring side planes of the test specimens mounted to the volunteers' foreheads show a significantly lower $(\mathrm{P}=0.008, \mathrm{P}=0.02, \mathrm{P}<$ $0.001, \mathrm{P}<0.001)$ deviation from the original angles when measured with Artec EVA ${ }^{\circledR}$. The divergences between the original angle and the angles between the left and the top planes as well as the angles between the left and the bottom planes are significantly lower $(\mathrm{P}<0.001)$ when measured with Artec $\mathrm{EVA}^{\circledR}$ for at the test specimens attached to the volunteers' cheeks. The deviations between the original angle and the other angles measured are not significantly different $(\mathrm{P}=0.077, \mathrm{P}=0.112)$ for the test specimens mounted to the volunteers' cheeks when measured with the two three-dimensional scanning systems (Figure 6).

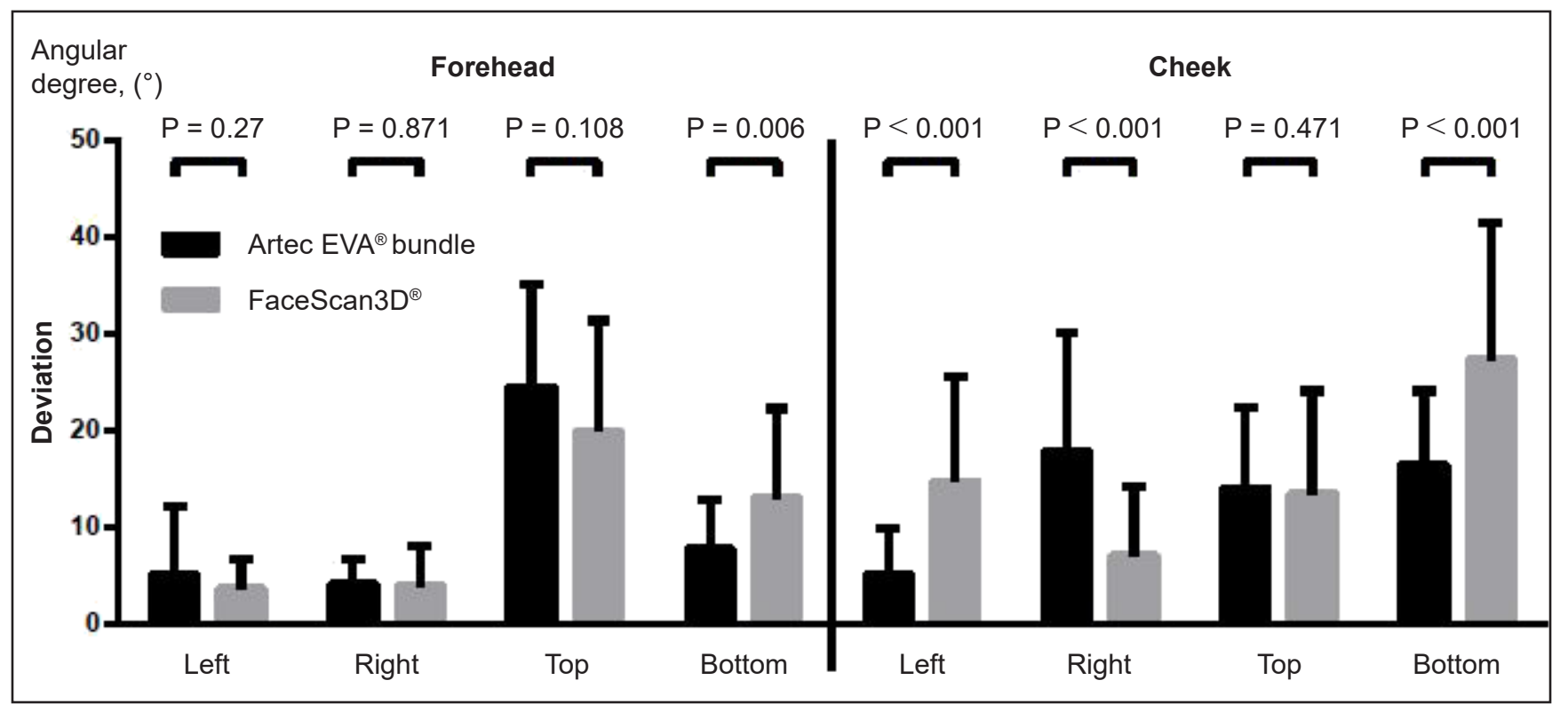

Figure 5. Boxplot showing mean deviation of angles between front plane and side planes of test specimen (angular degree, $\left[{ }^{\circ}\right]$ ) in scans using Artec EVA ${ }^{\circledR}$ and FaceScan $3 \mathrm{D}^{\circledR}$, as well as corresponding P-values.

Table 3. Mean deviation (M [SD]) of angles between neighbouring side planes according to original in degree

\begin{tabular}{|c|c|c|c|c|c|c|}
\hline & \multicolumn{2}{|c|}{ Artec $\mathbf{E V A}^{\circledR}$ bundle } & \multicolumn{2}{|c|}{ FaceScan3D $^{\circledR}$} & \multicolumn{2}{|c|}{ P-values } \\
\hline & Forehead & Cheek & Forehead & Cheek & Forehead & Cheek \\
\hline Right to top plane & $4.059(3.934)$ & $4.696(4.206)$ & $7.848(6.91)$ & $8.04(8.656)$ & $0.008^{\mathrm{a}}$ & $0.077^{\mathrm{b}}$ \\
\hline Left to top plane & $4.925(5.592)$ & $2.788(2.447)$ & $8.954(8.229)$ & $10.89(10.1)$ & $0.02^{\mathrm{a}}$ & $<0.001^{\mathrm{a}}$ \\
\hline Right to bottom plane & $2.349(1.699)$ & $4.854(4.998)$ & $5.784(4.65)$ & $8.101(8.24)$ & $<0.001^{\mathrm{a}}$ & $0.112^{\mathrm{b}}$ \\
\hline Left to bottom plane & $2.157(2.652)$ & $2.9(4.153)$ & $5.955(5.128)$ & $10.852(8.309)$ & $<0.001^{\mathrm{a}}$ & $<0.001^{\mathrm{a}}$ \\
\hline
\end{tabular}

${ }^{\text {a }}$ Statistically significant at the level $\mathrm{P}<0.05$ (Student $t$-test).

${ }^{b}$ No statistically significant at the level $\mathrm{P}<0.05$ (Student $t$-test).

$\mathrm{SD}=$ standard deviation 


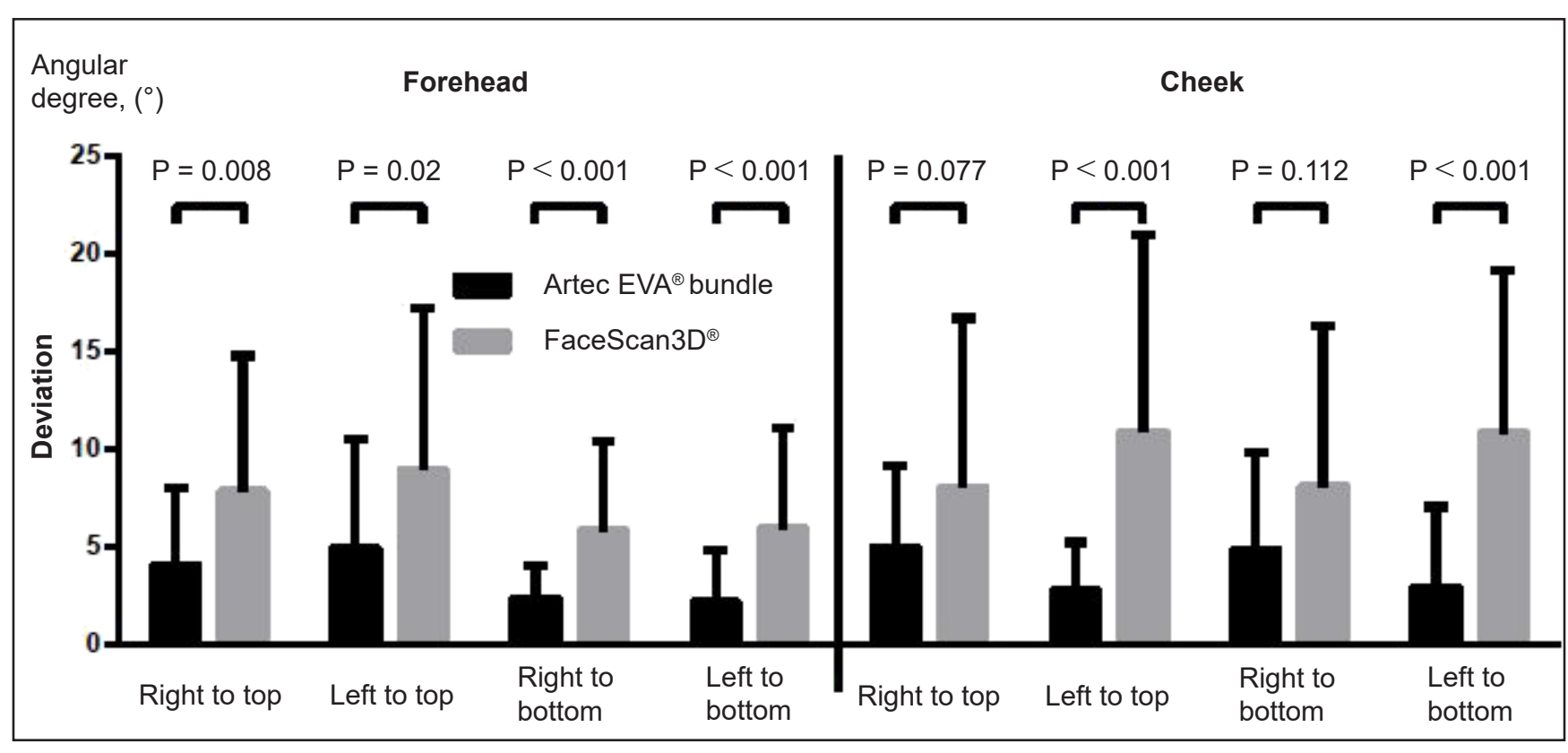

Figure 6. Boxplot showing mean deviation of angles between neighbouring side planes of test specimen (angular degree, $\left[^{\circ}\right]$ ) in scans using Artec $\mathrm{EVA}^{\circledR}$ and FaceScan3 $\mathrm{D}^{\circledR}$, as well as corresponding P-values.

\section{DISCUSSION}

In our study, a new feature of a three-dimensional scanner is used. To our knowledge, no other scanning system provides the possibility of creating bundles of up to four standalone scanners, limited by the PC used, to increase the field of view and accuracy of capturing data while scanning time is reduced. For creating a bundle of scanners, it is necessary to put them into a position to each other that does not change during the whole recording with this bundle. Therefore, the scanners have to be set up and have to be aligned before using them.

For aligning them, it is necessary that a small piece of the field of view of each scanner overlaps with the field of view of another one. Without that, it is not possible for the Artec Studio software to determine the scanners position in space. Setting up a bundle of two scanners took us nearly 15 min until the scanners where ready to capture the first object. Preparing FaceScan3D ${ }^{\circledR}$ took the examiner at most 3 min. Depending on the setting that the three-dimensional scanner should be used, the length of preparation time of a scanner bundle has to be considered.

For comparing the differences in the two scanning systems, we decided to use test specimens attached to volunteers' faces. These test specimens were mounted to the forehead in the middle of the face and the right cheek. Both test specimens were angled $90^{\circ}$ to each other and fixed to the faces so that one of the side planes faced the outer margin of the field of view of the scanning systems. As a test specimen we chose regular $4 \times 2$ Lego bricks. These are prismatic and provide sharp edges and $90^{\circ}$ angles. Because of this geometric appearance, more than just distances can be measured. Angles also can be measured that give information about the scanned form of the test specimen. Lego bricks deliver prominent geometric parts that are needed by the scanners to align the different frames taken to each other [23]. The Lego bricks have been dulled before capturing them because this results in better images. Without dulling them, the specular flares emitted by them lead to severe errors in capturing data [24]. After dulling them, they could be scanned in good quality.

To measure the accuracy of three-dimensional images, often landmarks set by the examiner are used [810,12-14]. An advantage of using test specimens together with Geomagic Studio is the possibility of marking whole planes up by the examiner and letting the software compute an equalisation plane. Even though Khambay et al. [12] and colleagues showed that the error is a mean between 0.06 and $0.07 \mathrm{~mm}$ and Ayoub et al. [10] showed a mean error of $0.2 \mathrm{~mm}$, it was our goal to automate the process of measuring as far as possible to reduce the error created by humans. In this analysis, the examiner marks the planes strictly to their edges and lets the software calculate the mean from numerous points. Every distance and angle mentioned in this study is calculated between these equalisation planes.

According to our results for the test specimen's dimensions, the deviation measured by FaceScan3D ${ }^{\mathbb{R}}$ is less than that measured with a bundle of two Artec EVA $^{\circledR}$ scanners. Not every discrepancy differs 
significantly from each other (Table 1 - 3). It stands out that the mean deviation of the angle between the front plane and the bottom plane on the forehead and the left plane on the cheek is significantly lower when recorded with Artec $\mathrm{EVA}^{\circledR}$ (Table 2). This is caused by their orientation towards the field of view of the Artec EVA $^{\circledR}$ scanners and leads to the idea that the field of view of only two coupled Artec EVA ${ }^{\circledR}$ devices is not big enough to scan a human face sufficiently. An interesting fact is the discrepancy of the angle between the two neighbouring side planes. The mean deviation captured with Artec EVA ${ }^{\circledR}$ is always lower than that captured with FaceScan3D ${ }^{\circledR}$ (Table 3). The most common reason is that a few recorded points of a plane are enough information for Artec Studio to determine the orientation of planes inside space and display them in the final three-dimensional model. Despite the bigger field of view, FaceScan3D ${ }^{\mathbb{B}}$ and the Slim3D software are not working this well.

Compared with other three-dimensional scanners used in the literature whose accuracy has been measured, like C3D Imaging System with a mean error of $0.83 \mathrm{~mm}$ determined by Ayoub et al. [10], GFM TopoCam or Polhemus FastSCAN with a mean error ranging between 0.05 and $1.49 \mathrm{~mm}$ determined by Eder et al. [8] as well as the error of the $3 \mathrm{dMD}$ system ranging from 0.067 to $0.74 \mathrm{~mm}$ as stated by Weinberg et al. [13], and ranging from 0 to $3.2 \mathrm{~mm}$ specified by Metzger et al. [14], the exactness of FaceScan $3 \mathrm{D}^{\circledR}$ for measuring distances with a mean $0.966 \mathrm{~mm}$ inaccuracy ranges in the same area. Using the bundle of two Artec EVA ${ }^{\circledR}$ scanners for scanning distances results in a mean inaccuracy of $2.997 \mathrm{~mm}$, which is nearly 3 times as much as the imprecision of FaceScan3D ${ }^{\circledR}$. This error of the scanner bundle can only be compared with the error created by the $3 \mathrm{dMD}$ scanning system according to Metzger et al. [14] Most other reviewed scanning systems result in lower errors. It could be possible that this larger error while using the bundle of two Artec $\mathrm{EVA}^{\circledR}$ scanners results from the technique used for recording the volunteers. Arranging the two scanners to the same height increases the field of view only horizontally and not vertically. Furthermore, the horizontal extension of the field of view is not as effective as using a mirror construction to capture more data like FaceScan3D ${ }^{\circledR}$ does. To increase the field of view vertically and horizontally, more than two scanners have to be bundled. Further research has to be done to evaluate the advantage of more than two bundled Artec EVA ${ }^{\circledR}$ scanners. It should be evaluated if an enlargement of the scanner bundle significantly improves the accuracy enough so that the capital asset for more scanners and the length of time for setting up and calibrating the scanners are worthwhile.

\section{CONCLUSIONS}

Compared to FaceScan3D ${ }^{\circledR}$, a bundle of two Artec EVA $^{\circledR}$ scanners provides different levels of accuracies depending on the location and configuration of measured parameters. The accuracy measured for both scanners is inside the range found in the literature for other facial scanning systems. At present, sometime is necessary to set up the scanner bundle, and the second scanner is a major capital asset. Determining if a single or a bundle of more than two Artec EVA ${ }^{\circledR}$ scanners results in a higher accuracy has to be evaluated in further studies.

\section{ACKNOWLEDGEMENTS AND DISCLOSURE STATEMENTS}

The authors report no conflicts of interest related to this study.

This research did not receive any specific grant from funding agencies in the public, commercial, or notfor-profit sectors.

\section{REFERENCES}

1. Ayoub N, Ghassemi A, Rana M, Gerressen M, Riediger D, Hölzle F, Modabber A. Evaluation of computerassisted mandibular reconstruction with vascularized iliac crest bone graft compared to conventional surgery: a randomized prospective clinical trial. Trials. 2014 Apr 9;15:114. [Medline: 24716651] [PMC free article: 3998950] [doi: 10.1186/1745-6215-15-114]

2. Zinser M, Zoeller J. Computer-Designed Splints for Surgical Transfer of 3D Orthognathic Planning. Facial Plast Surg. 2015 Oct;31(5):474-90. [Medline: 26579863] [doi: 10.1055/s-0035-1565010]

3. Wermker K, Kleinheinz J, Jung S, Dirksen D. Soft tissue response and facial symmetry after orthognathic surgery. J Craniomaxillofac Surg. 2014 Sep;42(6):e339-45. [Medline: 24529350] [doi: 10.1016/j.jcms.2014.01.032]

4. van der Meer WJ, Dijkstra PU, Visser A, Vissink A, Ren Y. Reliability and validity of measurements of facial swelling with a stereophotogrammetry optical three-dimensional scanner. Br J Oral Maxillofac Surg. 2014 Dec;52(10):922-7. [Medline: 25219776] [doi: 10.1016/j.bjoms.2014.08.019] 
5. Ayoub AF, Xiao Y, Khambay B, Siebert JP, Hadley D. Towards building a photo-realistic virtual human face for craniomaxillofacial diagnosis and treatment planning. Int J Oral Maxillofac Surg. 2007 May;36(5):423-8. [Medline: 17428638] [doi: 10.1016/j.ijom.2007.02.003]

6. Verzé L, Bianchi FA, Dell'Acqua A, Prini V, Ramieri GA. Facial mobility after bimaxillary surgery in class III patients: a three-dimensional study. J Craniofac Surg. 2011 Nov;22(6):2304-7. [Medline: 22134264] [doi: $10.1097 / \mathrm{SCS} .0 \mathrm{~b} 013 \mathrm{e} 318232 \mathrm{a} 7 \mathrm{f0}$ ]

7. Modabber A, Rana M, Ghassemi A, Gerressen M, Gellrich NC, Hölzle F, Rana M. Three-dimensional evaluation of postoperative swelling in treatment of zygomatic bone fractures using two different cooling therapy methods: a randomized, observer-blind, prospective study. Trials. 2013 Jul 29;14:238. [Medline: 23895539] [PMC free article: 3729713] [doi: $10.1186 / 1745-6215-14-238]$

8. Eder M, Brockmann G, Zimmermann A, Papadopoulos MA, Schwenzer-Zimmerer K, Zeilhofer HF, Sader R, Papadopulos NA, Kovacs L. Evaluation of precision and accuracy assessment of different 3-D surface imaging systems for biomedical purposes. J Digit Imaging. 2013 Apr;26(2):163-72. [Medline: 22584773] [PMC free article: 3597967$]$ [doi: 10.1007/s10278-012-9487-1]

9. Lübbers HT, Medinger L, Kruse A, Grätz KW, Matthews F. Precision and accuracy of the 3dMD photogrammetric system in craniomaxillofacial application. J Craniofac Surg. 2010 May;21(3):763-7. [Medline: 20485043] [doi: 10.1097/SCS.0b013e3181d841f7]

10. Ayoub A, Garrahy A, Hood C, White J, Bock M, Siebert JP, Spencer R, Ray A. Validation of a vision-based, three-dimensional facial imaging system. Cleft Palate Craniofac J. 2003 Sep;40(5):523-9. [Medline: 12943434] [doi: 10.1597/02-067]

11. Artopoulos A, Buytaert JA, Dirckx JJ, Coward TJ. Comparison of the accuracy of digital stereophotogrammetry and projection moiré profilometry for three-dimensional imaging of the face. Int J Oral Maxillofac Surg. 2014 May;43(5): 654-62. [Medline: 24225265] [doi: 10.1016/j.ijom.2013.10.005]

12. Khambay B, Nairn N, Bell A, Miller J, Bowman A, Ayoub AF. Validation and reproducibility of a high-resolution three-dimensional facial imaging system. Br J Oral Maxillofac Surg. 2008 Jan;46(1):27-32. [Medline: 17561318] [doi: 10.1016/j.bjoms.2007.04.017]

13. Weinberg SM, Naidoo S, Govier DP, Martin RA, Kane AA, Marazita ML. Anthropometric precision and accuracy of digital three-dimensional photogrammetry: comparing the Genex and 3dMD imaging systems with one another and with direct anthropometry. J Craniofac Surg. 2006 May;17(3):477-83. [Medline: 16770184] [doi: 10.1097/00001665-200605000-00015]

14. Metzger TE, Kula KS, Eckert GJ, Ghoneima AA. Orthodontic soft-tissue parameters: a comparison of cone-beam computed tomography and the 3dMD imaging system. Am J Orthod Dentofacial Orthop. 2013 Nov;144(5):672-81. [Medline: 24182583] [doi: 10.1016/j.ajodo.2013.07.007]

15. Modabber A, Räsch M, Ghassemi M, Knobe M, Gerressen M, Ghassemi A, Rana M, Hölzle F. Noninvasive 3-dimensional evaluation of periorbital asymmetry in isolated unilateral orbital floor fractures. Oral Surg Oral Med Oral Pathol Oral Radiol. 2014 Oct;118(4):392-9. [Medline: 25179129] [doi: 10.1016/j.0000.2014.05.010]

16. Rana M, Gellrich NC, Ghassemi A, Gerressen M, Riediger D, Modabber A. Three-dimensional evaluation of postoperative swelling after third molar surgery using 2 different cooling therapy methods: a randomized observer-blind prospective study. J Oral Maxillofac Surg. 2011 Aug;69(8):2092-8. [Medline: 21496998] [doi: 10.1016/j.joms.2010.12.038]

17. Rana M, Gellrich NC, Joos U, Piffkó J, Kater W. 3D evaluation of postoperative swelling using two different cooling methods following orthognathic surgery: a randomised observer blind prospective pilot study. Int J Oral Maxillofac Surg. 2011 Jul;40(7):690-6. [Medline: 21411291] [doi: 10.1016/j.ijom.2011.02.015]

18. Rana M, Gellrich NC, von See C, Weiskopf C, Gerressen M, Ghassemi A, Modabber A. 3D evaluation of postoperative swelling in treatment of bilateral mandibular fractures using 2 different cooling therapy methods: a randomized observer blind prospective study. J Craniomaxillofac Surg. 2013 Jan;41(1):e17-23. [Medline: 22626630] [doi: 10.1016/i.jems.2012.04.002]

19. Döppes D, Rosendahl W, Alterauge A. Vom 3D-Scan bis zum 3D-Druck-Allgemeine Grundlagen und Praxisbeispiele aus dem Museumsbereich. Der Präparator. 2014;60:36-43.

20. Elburg R, Reuter T, Innerhofer F. 3D-Dokumentation und Visualisierung eines Frühneolithischen Holzbrunnens Erfahrungen und Perspektiven. Conference EVA Berlin 2014: Elektronische Medien \& Kunst, Kultur und Historie; 2014 Nov 5-7; Berlin, Germany. [URL: http://www.eva-berlin.de]

21. Henson KD. Stories in Bone Still Told: Digitization and Replication of the Clover Site, Fort Ancient Human Remains [dissertation]. Theses, Dissertations and Capstones: Marshall University. Marshall Digital Scholar; 2015 May. [URL: http://mds.marshall.edu/etd/903]

22. Mikolajek M, Machacek Z, Koziorek J. Modern Sensor Technology for Alphanumeric Recognition in Metallurgy Industry. Elektronika ir Elektrotechnika. 2014 May;20(5): 3-7. [doi: 10.5755/j01.eee.20.5.7090]

23. Battle E, Matabosch C, Salvi J. Overview of 3D registration techniques including loop minimization for the complete acquisition of large manufactured parts and complex environments. Eighth International Conference on Quality Control by Artificial Vision; 2007 May 23-25; Le Creusot, France. Spie. 2007 May;635605. [doi: 10.1117/12.736695] 
24. Sadlo F, Weyrich T, Peikert R, Gross M. A practical structured light acquisition system for point-based geometry and texture. Proceedings Eurographics/IEEE VGTC Symposium Point-Based Graphics. 2005 Jun. 89-145. [doi: 10.1109/PBG.2005.194069]

\section{To cite this article:}

Modabber A, Peters F, Brokmeier A, Goloborodko E, Ghassemi A, Lethaus B, Hölzle F, Möhlhenrich SC.

Influence of Connecting Two Standalone Mobile Three-Dimensional Scanners on Accuracy Comparing with a Standard Device in Facial Scanning

J Oral Maxillofac Res 2016;7(4):e4

URL: http://www.ejomr.org/JOMR/archives/2016/4/e4/v7n4e4.pdf

doi: $\underline{10.5037 / j o m r .2016 .7404}$

Copyright (C) Modabber A, Peters F, Brokmeier A, Goloborodko E, Ghassemi A, Lethaus B, Hölzle F, Möhlhenrich SC. Published in the JOURNAL OF ORAL \& MAXILLOFACIAL RESEARCH (http://www.ejomr.org), 28 December 2016.

This is an open-access article, first published in the JOURNAL OF ORAL \& MAXILLOFACIAL RESEARCH, distributed under the terms of the Creative Commons Attribution-Noncommercial-No Derivative Works 3.0 Unported License, which permits unrestricted non-commercial use, distribution, and reproduction in any medium, provided the original work and is properly cited. The copyright, license information and link to the original publication on (http://www.ejomr.org) must be included. 